\title{
Knowledge management as a key stone \\ of sustainable welfare in the Italian rural areas
}

\author{
by Francesco Zecca* and Natalia Rastorgueva**
}

Abstract

Sustainable well-being in the rural areas directly depends on their sustainable development. However, sustainable management in contemporary agriculture does not come easy for farmers due to different challenges and quality standards. To meet these challenges and to achieve sustainable development, the agricultural enterprises need an informational support. Therefore this article offers knowledge management as a tool for facilitating agricultural performance and enhancing quality of rural life.

Practical application of knowledge management is quite complicated due to its intangible characteristics. Hence, the paper is targeted at developing sustainable organizational model of knowledge management affordable for small and medium enterprises. This model was created after content-analysis of the literature and was verified through an executed survey. The Italian agriculture was considered as a context for this study.

Key words: knowledge management, sustainability, well-being, Italian agriculture, dissemination.

\section{Riassunto}

Il Knowledge Management come strumento fondamentale del benessere sostenibile nelle aree rurali Italiane

Il benessere nelle aree rurali dipende direttamente dalla sostenibilità del loro sviluppo. Tuttavia una gestione sostenibile dei processi produttivi nelle aree rurali non è semplice da parte degli agricoltori a causa della necessità di affrontare le diverse problematiche correlate all'applicazione dei principi di sostenibilità. Per rispondere a queste sfide le imprese agricole hanno bisogno di un supporto informativo in grado di indirizzarne le scelte. Il presente contributo intende dimostrare come il knowledge

\footnotetext{
* Associate Professor of Agricultural Economics, Department of Management, Faculty of Economics, Sapienza University of Rome, Via del Castro Laurenziano 900161 Roma, tel.+39 3398067105. E-mail: francesco.zecca@uniroma1.it.

** PhD, Department of Management, Faculty of Economics, Sapienza University of Rome, Via del Castro Laurenziano 900161 Roma, tel. +393807984533. E-mail: natalia.v.rastorgueva@gmail.com.
}

Rivista di Studi sulla Sostenibilità, (ISSN 2239-1959, ISSNe 2239-7221), 2017, 1 DOI: 10.3280/RISS2017-001012 
management può favorire la sostenibilità nelle aree rurali migliorandone la qualità della vita.

Lo sviluppo del modello ha avuto come riferimento dimensionale le piccole e medie imprese. Il modello è stato messo a punto attraverso l'analisi della letteratura ed una verifica empirica condotta attraverso la somministrazione di un questionario. Come contesto relazionale è stato preso a riferimento il settore agricolo Italiano.

Parole chiave: knowledge management, sostenibilità, benessere, agricoltura italiana, disseminazione.

\section{Introduction}

Currently, sustainability and sustainable development, as well as their dimensions, are the most discussed concepts. The global vision towards sustainable development was laid out in the 2030 Agenda for Sustainable Development, which includes 17 goals, and integrates in balanced manner the three dimensions - economic, environmental and social. All these goals and dimensions are related to agriculture. Namely agriculture, due to its strict links to nature, remains a hazardous industry and needs the sustainable development as for farms as for rural areas.

On the other hand, agriculture as an industry provides an occupation for rural people and quality food products for every society. However, the contemporary European standards of the food quality are very high and compliance to them requires additional costs and an appropriate information support. Agricultural economy and environment are linked through many complex relationships (Perman et al., 2011); and farmers should consider this interdependency for adapting their systems to changing conditions in order to achieve long-term sustainability and welfare (Committee, 2010).

Under these strict conditions, agricultural enterprises need sustainable management and information support. Thus, this research offers a knowledge management $(\mathrm{KM})$ as a tool for sustainable development in the agricultural context.

Nowadays overall use of information in business performance has became de facto standard; and an effective organisation of information flows or $\mathrm{KM}$ is an important strategic asset for a profitable activity of a contemporary enterprise. Recent scientific literature does not clearly define a well-organised model of KM. Some describe this model as "effective", "success" or "mature", but for this study, the most appropriate definition of functional KM model is "sustainable". Therefore, the main research objective of the 
paper is elaborating sustainable model of KM adapted to the agricultural context. Sustainability of KM is considered as an ability to provide sufficient information for solving a certain problems. As KM is context-specific issue, its sustainability should be approved on the practice and pursue a certain functions in a certain circumstances.

$\mathrm{KM}$ is one of the most quickly developing concepts of management (Lendzion, 2015), nevertheless, only existence of KM is not a sufficient condition for a competitive advantage, but it is crucial for farmer's systemic thinking and enhancing an agricultural performance.

Thus, the first research question (RQ1) of the study is follow: how can small and medium-sized agricultural enterprises adopt KM practices?

The article highlights agricultural small and medium-sized enterprises, due to their dominance within the European agri-food industry. The selection of the Italian case is conditioned by two reasons: firstly, Italy as the example of the EU country is regulated by European legislative norms; secondly, Italian natural, climate and socio-cultural features have a great impact on the development of rural areas, where the world-famous food is produced.

A similar research was executed by Johnson (2017). This research goes beyond his study, as highlights the agricultural context and aims to answer the second research question (RQ2): which role plays KM in the sustainable development and in the sustainable welfare of the rural territories?

The paper could contribute to development and practical application of $\mathrm{KM}$ in the agricultural context, because in the contemporary conditions an adoption of KM allows to improve well-being of people in rural areas.

\section{Methodology}

In order to answer the research questions and to develop a sustainable model of KM, this paper includes four-fold methodology. The first part is based on the literature review, which discusses the most important theoretical issues: sustainability and welfare, KM and its application in the agricultural context, features of Italian agriculture and agricultural KM system. The second part of the research includes content analysis in order to select the main theoretical factors necessary for organising KM process. KM was developed and widely applied during the recent years, thus the period of the latest decade (2005-2015) seems more interesting for content analysis. Therefore, 105 academic articles of the specified period were selected in scientific databases as Scopus, EBSCO and Sciencedirect. 105 articles it is not 
a huge number, but highlighted scientific focus is very narrow and limited by two scientific fields: KM and agricultural context.

Studied articles were systematised and elaborated by Excel. The results of the two previous parts form the basis of the developed knowledge management model (KMM) in the third part of the research.

Finally, the last part of the research includes the survey to verify the developed KMM. The survey employed questionnaire approach, as the most appropriate method for KM research. In order to estimate the developed KMM from farmers' viewpoint, the questionnaire contains 13 close-ended questions to clarify the next issues: farmers' awareness towards $\mathrm{KM}$; farmers' knowledge needs (type and form of required information); the role of extension, its utility for farmers; farmers' attitude towards factors of KMM; farmers' readiness to implement the developed KMM.

Given the features of agricultural context, the survey has anonymous character and includes simple close-ended questions translated to Italian. Online questionnaire was executed through Google platform and was sent to 420 agricultural small and medium-sized enterprises situated in all parts of Italy. Thus, executed survey allows to improve developed KMM and to make theoretical model more affordable for agricultural context.

\section{Background}

\subsection{Sustainable well-being in rural areas and role of KM in it}

Since 1960's when the role of agricultural sector in an economy was reconsidered, the great attention was paid to agricultural development and later to rural development. Nowadays, development and well-being of a society in rural areas remain an actual issues as for rural population as for policymakers. Different countries variously define the concept of welfare, but in generally, welfare can be considered as a measure of the well-being of society as for individual level as for national.

Some authors (Weber et al., 2002; Milbourne, 2010; Berionni, 2013) underline the role of policy in the sustainable regional well-being. Besides, as well-being of a society is based on the three dimensions of sustainability and scientists consider the conception of well-being from these viewpoints. Thus, Daly (2011) underlines the common environmental challenge for societies: how to secure welfare in a context of decreasing resources. Diener et al. (2002) and Midgley (1995) emphasised a social site in the well-being cate- 
gory and defined it as individuals' emotional responses and domain satisfactions, or as global judgments of life satisfaction. As for economic pillar, Porterfield (1998) and Weber (2002) linked welfare to employment.

Turner et al. (1994) connected sustainable development of a society with the long-term economic development. Time dimension of sustainability was underlined in the Brundtland Report (1987), it was defined as a possibility for future generations to receive some outcome (Fleurbaey, 2015).

During the last decade, there were several attempts to measure level of well-being of a society:

- Gross Domestic Product (GDP) was usually used as an essential instrument for well-being assessment (Cancila, Zecca, 2010), is an indicator of economic performance and social progress does not take in account non-monetary costs and benefits (Stiglitz et al., 2009).

- Gross National Wellness Index is a socioeconomic development and measurement framework. This index consists of seven dimensions: economic, environmental, physical, mental, work, social, and political.

- The Index of Sustainable Economic Welfare was introduced by Daly and Cobb (1989) to adjust some aspects of GDP (Chelli et al., 2013).

Besides these indicators, there are several other instruments to measure level of social well-being, however comparison of cross-country indicators is difficult, due to problems in the availability and in the comparability of the data. Hence, measurement of the well-being seems more accessible on the regional level (Chelli et al., 2013).

Well-being of any society seems a complicated phenomena and a perfectly balanced system, based on economics. Therefore it is very complicated to enhance any issue of this equilibrium without declining the other aspects, and, according to Pareto, any improvement can be made to at least one participant well-being without reducing any other participants well-being (Midgley, 1995). From this viewpoint, application of information or KM practices seems the most convenient way to achieve sustainable development an regional level.

Given, $\mathrm{KM}$ is an integral part of enterprise management that covers all relevant management areas (Krumina et al., 2015), practices of KM (knowledge sharing and business-knowledge process) directly contribute to the improvement of organizational performance (Oyemomi et al., 2016).

Thus, within an enterprise well-being is a motivation for employees to apply knowledge sharing behaviour thereby increasing success of an organization (Chumg et al., 2015). 
As demonstrates Figure 1., in theory, KM indirectly contributes to the rural areas through enhancing performance of farms and agricultural enterprises.

Figure 1 - Indirect contribution of KM to well-being of rural society

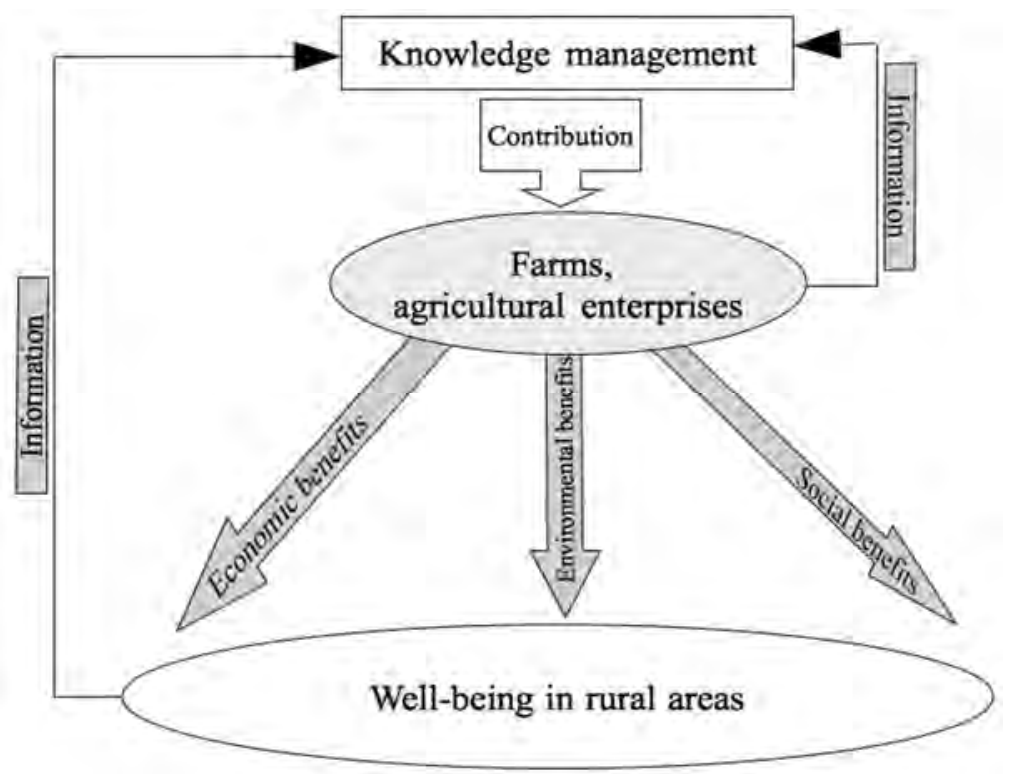

The usage of information allows to achieve a competitive advantage for enterprises and to provide different benefits to the rural areas: economic benefits (decreased incomes, economic stability decreases rural-urban migration and prevents depopulation of rural areas); ecological benefits (decreased carbon footprint, preserved an ecosystem); social benefits (cultural heritage, increased social inclusion and social cohesion).

Furthermore, rural society in its turn creates an indigenous knowledge which fills KM of farms. Thus, contribution of KM to farms seems more significant than information flows from society, and this continuous information movement allows sustaining the well-being of the rural society.

Kevany and MacMichael (2014) considered the capacities of community to adapt to external and internal stresses as important characteristics of rural well-being. KM seems a perfect tool to build this capacity, as well as to alleviate certain problems: to mitigate and to govern risks (Mauelshagen et al., 2014); to improve logistic planning and facilitate as local delivering as entire food supply chain (Zecca and Rastorgueva, 2014); to smooth information asymmetry within the food market (Zecca and Rastorgueva, 2016). 


\subsection{Theoretical issues of Knowledge management}

There is no unified definition of "knowledge management". It was described as an umbrella term which refers to any deliberate efforts to manage the knowledge (Hislop, 2009); as the management of corporate knowledge and intellectual assets (Gupta, 2000); as all methods and tools that contribute to the promotion of an integrated core knowledge process (Mertins, 2003).

The essence of KM is developing a special dynamic capability that aligns firms' knowledge resources with the needs of the changing conditions; and governance mechanisms and learning routine play the main role in this process (Chen and Fong, 2015).

One of the most significant enablers of KM is leadership (Aurum et al., 2008). The difficulty of managing knowledge, as a key corporate resource, has made role and responsibility of leadership as critical (Lakshman, 2008). A knowledge leader is the catalyst for a knowledge-sharing culture, owner of the infrastructure specifications that facilitate knowledge transfer and storage, and maintainer of the learning system (Yang et al., 2014; Rasmus 2000).

The Resource-based view (RBV) as the dominant theoretical perspective in strategic management literature (Chuang, 2004), was originally developed to examine the relationships between the resources of a firm and its performance (Canavari, 2012). RBV focuses on resources within an organization rather than the external environment. The KM model based on RBV should have an internal focus, and might be augmented by accounting for environmental factors such as dynamism (Pee, Kankanhalli, 2016). RBV considers the firm the acquisition of external knowledge more as a learning opportunity than as a cost, following a complementary vision (Nieves, 2013; Nonaka et al., 2000; Tseng et al., 2011).

Within the RBV, KM resources are classified as technical and social (Chuang, 2004), and approaches of KM are divided as technology-oriented and human-oriented (Maier, 2007). Authors have different opinions which approach is the most preferable. In the same time some assume, that a holistic approach could overcome the distinction between human-oriented and technology-oriented KM (Maier, 2007) and achieve the balance between technological and social facet of the organization (Bhatt, 2001).

Both technological and social issues are necessary elements for KM success, which is described as an ability to leverage knowledge resources to achieve actionable outcomes (Jennex et al., 2010). 


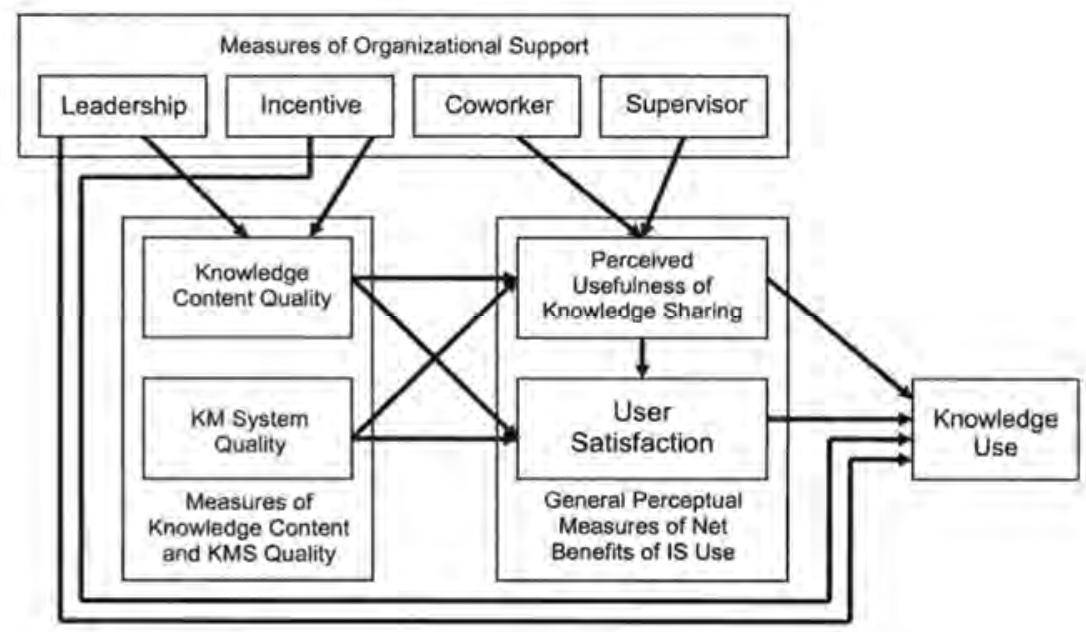

Source: Kulkarni et al. 2006

However, the general meaning of $\mathrm{KM}$ success is capturing the right knowledge, getting the right knowledge to the right user, and using this knowledge to improve individual performance (Wang and Yang, 2016).

To satisfy this definition, a KM success model needs to cover the effect of different types of activities and mechanisms (Kulkarni et al., 2006); and to apply mixed strategies in its given situations (Kim et al., 2014).

Contemporary literature offers two the most interesting models of KM success. Both models contain different components and mechanisms, with a different position of a Knowledge User.

The first model (Fig. 2), studies knowledge sharing and use from a knowledge worker perspective as an indication of success of KM initiative. Besides, Kulkarni et al. (2006) underlined a significance of knowledge content quality and KM System Quality, and important determinants of Knowledge Use through their intermediate effect on User Satisfaction.

The second model of KM success, is demonstrated on Figure 3. 


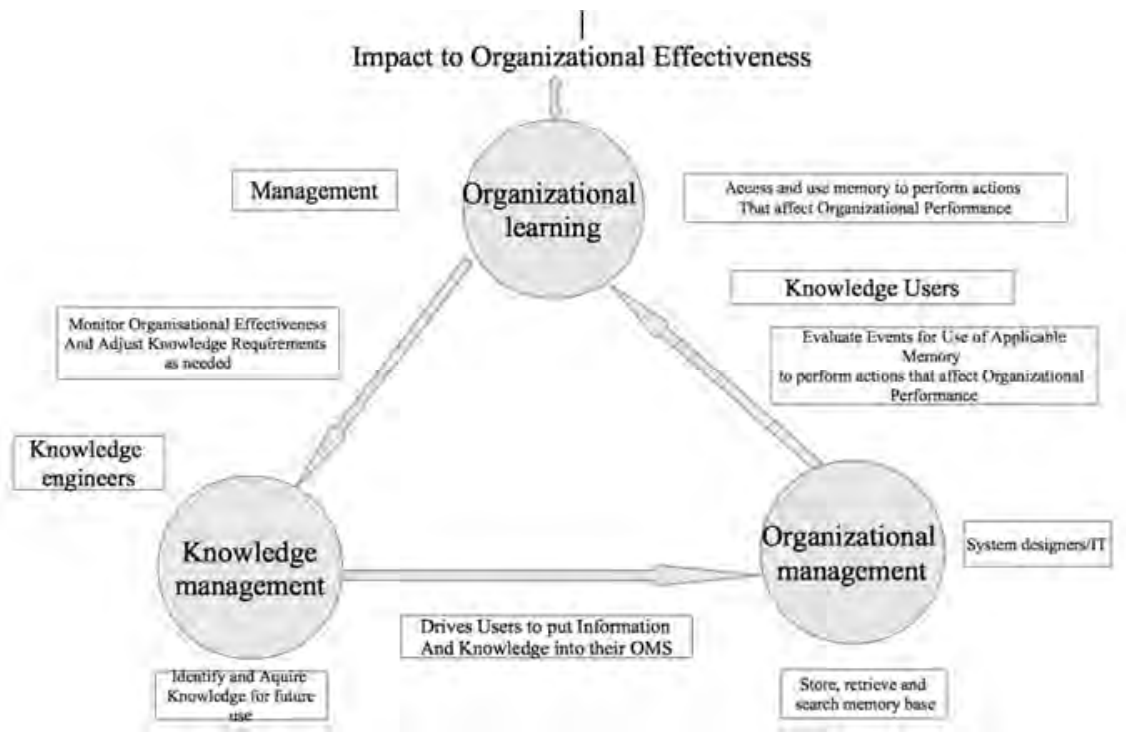

Source: Jennex and Olfman (2010)

It describes user's satisfaction as a construct that measures perceptions of $\mathrm{KM}$ by users, and as one of the most frequently measured aspects of information system success, constructed with a multitude of measurement instruments.

\subsection{Knowledge management application in agricultural context}

Agriculture as an industry closely linked with the natural factors, it characterises by the next features, which regulate all activities from the organisation of enterprise to food sale: seasonality, outdoor character of performance affected by variations in temperature, and perishability of food products determines a tight timing constrains for its store and trade. These features stipulate a hazardous character of agricultural performance. Contemporary agriculture is becoming more knowledge-intensive, changing rapidly, and making farm management more complex. Skills and knowledge are critical for farmer's success. Though, practical dissemination of information in agriculture faces the next problems: user variety, linkage of disciplines; low access to information (Carrascal et al., 1995). 
Agricultural knowledge base as an asset of KM, is composed of scientific or specific knowledge linked to agricultural production and to innovations in that production. The concept of "agricultural knowledge system" embraces all the institutions, advisers, education and research involved in the construction of a sustainable agriculture (Marianne Cerf et al., 2000). KM in the context of rural development involves the realisation of the main functions of management focused on the resources of personalised, codified and established knowledge, and the processes with their participation (Ziemiańczyk et al., 2014).

The Farm Advisory System (FAS) is an essential tool for a successful implementation of the Common Agricultural Policy (CAP). The mission of the FAS includes: farmer's support in their efforts to comply with the EU's legal requirements relating to the environment, food safety, animal health and welfare; farmers assistance to adhere "cross-compliance" requirements and to avoid losing CAP payments (EC Report, 2010).

An important part of FAS, agricultural extension service, is a key factor in the innovating agriculture; it remains the main source of knowledge for farmers in developing countries.

Agricultural extension and advisory services can be defined as systems and mechanisms designed to create and strengthen the capacity of rural farmers through providing access to information and technologies and enhancing agricultural skills and practices (Mbo'o-Tchouawou and Colverson, 2014).

Extension undertakes a non-formal educational and organizational functions used to facilitating rural and agricultural development. It has a wide range of purposes, from technology transfer to problem-solving educational approaches or participatory programmes aimed at alleviating poverty and advancing community development (Rivera and Quamar, 2003).

Measuring impact of agricultural $\mathrm{KM}$ and extension is a complicated issue due to intangible character knowledge and information, and many factors affecting to agricultural performance. In order to estimate an impact of extension some authors offer to use monitoring as it helps to ensure the implementation of extension programmes and takes into account the interests of various stakeholders.

\subsection{The Italian case of agricultural extension and knowledge man- agement system}

The Italian Agricultural Knowledge System (AKIS) is characterised by different organisational models, working methods in all the macro-components recognized by OECD: Higher Education, Research and Development, 
and extension systems. The main target of AKIS is to meet farmer needs concerning innovative and more rational productive processes that improve agricultural products, decrease costs and lower the negative impact of agricultural processes on the environment (OECD).

Italian extension and the support system, as a part of AKIS, refer to a unique, complex and evolving entity which usually covers basic/specialised technical and financial extension support to farms and farmers, as well as all possible forms of information and innovation dissemination that enable farms to express their economic and social potential.

The Italian framework of advisory services is very complex due to several institutional levels which are responsible for the different components of extension. Each Italian region has its own Department of agriculture and its own unique organisation of research and advisory services. Therefore there are 21 different advisory services in Italy (Caggiano, 2014), with different financing principles: $33 \%$ of them are funded by regional institutions and $67 \%$ by other institutions; in the same time $85 \%$ are financed by public funds and $15 \%$ by private (Vagnozzi, 2008).

Extension coordinated by the public organizations may be managed and implemented by different organisations, including private ones in some cases (Materia, 2012). The public extension services tend to focus on "government driven" programs such as land reform and therefore reduce its ability to supply proper services to the "private driven" sector (commercial farming).

Commercial farmers look for alternative extension services, which are normally available at a cost. If the alternative service offers better quality, the farmers are willing to pay a certain price for it. However, most Italian farms are small and could not afford expensive extension services, yet they are not satisfied by the services offered by the government (Jordan, Nell and Zecca, 2004).

Extension and advisory services help farmers to enable their business and to use innovations under conditions of changing world. However, adoption of agricultural innovations depends on their affordability for farmers, and financial aspect plays for it an important role. Prager et al. (2016) assumed that commercialisation of farm advice affects the quality of services. Commercialised advice has several advantages but only for clients with sufficient financial capacity, whilst public support is important to improve the knowledge flows between public research and private organisations.

As Italian AKIS as Italian extension need to improve their organisation in order to interact more effectively and efficiently with policy makers and with farmers (Materia, 2012; Caggiano, 2014). 


\section{Results and Discussions}

As the result of content analysis, there were selected 4 main factors: indigenous (local) knowledge, knowledge transfer, learning process and knowledge sharing (Fig. 4).

Figure 4 - Selected factors for agricultural KM model

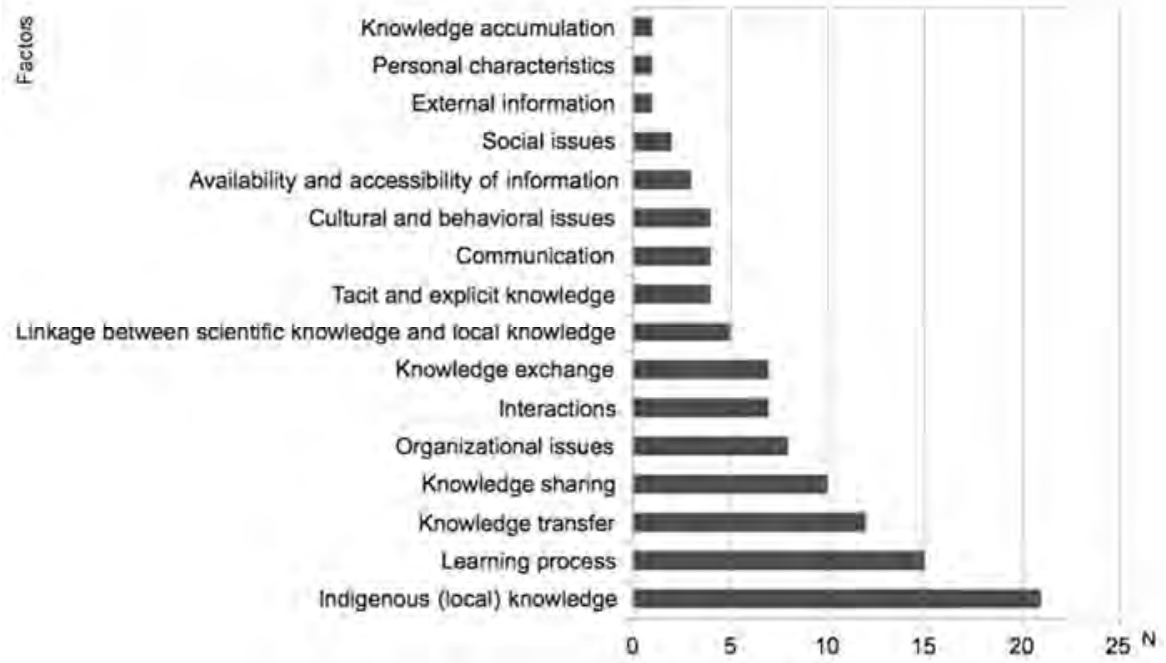

Knowledge transfer is an experience exchange between units of an enterprise to improve performance (Argot and Ingram, 2000), whilst knowledge sharing is a process of exchanging knowledge among individuals, a community and within an organisation (Kumaresan and Liberona, 2013).

Learning process is a cumulative process where individuals gradually internalise complex and abstract entities (concepts, categories, and patterns of behaviour or models) (Nijhof et al., 2002).

Indigenous (local) knowledge is immersed in the whole culture and is recreated through generations; it is the result of the quotidian interactions in indigenous peoples' territories (Semali, 2002).

These factors compose the central part of the theory-based KM model (Fig. 5), as well as leadership, due to its crucial role for KM routine (Yang et al., 2014). 


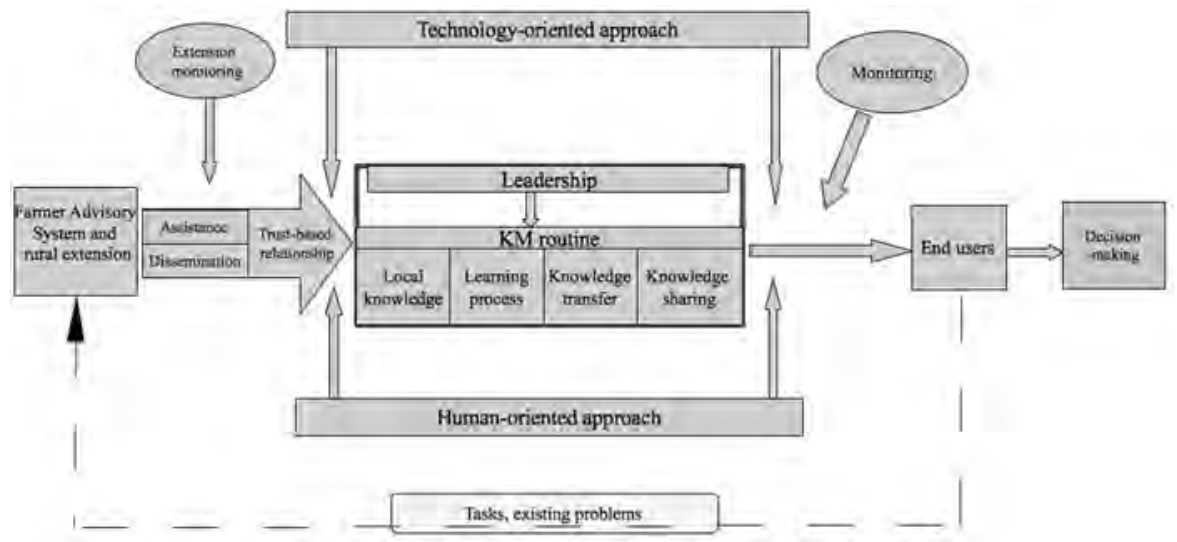

Besides the central part, developed KMM includes both aforementioned approaches: human-oriented (social aspect, communication and knowledge sharing) and technology-oriented (technical devices, computer-supported databases).

The model has problem-solving focus, it means that formulated tasks and problems are addressed to advisory services, which form the external part of the KMM. They provide an information support in form of assistance or dissemination of information, contacts of advisory services and farmers should be based on trust.

The model satisfies to the three pillars of sustainability. Thus, from the economic viewpoint, KMM should have a quite low cost and will enhance a performance of an enterprise. From the social viewpoint, KMM will improve relations within an enterprise, and skills of staff. From the ecological viewpoint, KMM will decrease office paper consumption.

However, sustainable functioning of KMM requires monitoring of $\mathrm{KM}$ success. Regular monitoring as an integral part of KMM is a necessary element for detection barriers to knowledge flow. For sustainable functioning of the developed model is necessary to divide monitoring process into two parts: extension monitoring, which regulates quantity and quality of information provided by extension services, its costs and timeliness; and KM monitoring, which controls the results of the elaborated KMM and information utility for users.

Hereafter the KMM was verified among Italian farmers. 420 on-line questionnaires were distributed throughout the country. After executed survey, it may say the follow. 
The first question of the survey regarded the age of the respondents, as it characterises a farmer's propensity to innovate: the older the age of the owners the less likely they are to innovate (Szirmai et al., 2011). Ageing farming population is a relevant problem of Italian agriculture and about $70 \%$ of farmers are above 50 years in 2010 . However, the results of this research demonstrate that more than half of respondents are younger than 45 .

According to the survey, only $40 \%$ of respondents use any practices of $\mathrm{KM}$ in their enterprises. The reasons of the quite low percentage can be different, for instance, lack of an appropriate devices, low access to needed information, low quality of advisory services etc.

All respondents have demonstrated their willingness to enhance KM. For $35 \%$ of respondents the issue of $\mathrm{KM}$ efficiency is the most relevant and about $40 \%$ of respondents have pointed out reducing of KM costs as the most important issue in improvement of KM. Therefore, level of costs and received results are crucial in the KM organization.

The survey revealed that the market information (current prices, new markets, supply chain issues etc.) is the most required by respondents than technological information or financial aspects. However, this information has an external character, and needs reliable information source, such as extension services.

The most respondents pointed out limited time and lack of qualified staff as the main impediments for rational organisation of KM. These obstacles have the next reasons: presence of many farmers' duties and lack of sufficient time to implement or reorganize KM system.

According to $66 \%$ of respondents, a positive impact of $\mathrm{KM}$ on the agricultural performance is the main criterion of effective KM, while user's satisfaction and presence of sufficient information were evaluated as not significant criteria.

Concerning farmers' perception of information and consequently, type of presented information, $41 \%$ of respondents would like to receive information in figures and $35 \%$ need experts' advice. This fact can improve the organisation of knowledge flows in order to receive necessary results, for example, relevant information should be systematised in diagrams and figures, or expert advises received in meetings.

The survey has confirmed the role of the agricultural extension as the main external information source for farmers: more than $60 \%$ of respondents have emphasised the principal part of advisory systems in informational provision. Negative attitude of the rest farmers is rooted in the regional differences in prices and quality of advisory services. 
The majority of interviewed farmers assumed that KM improves farmer's skills in all aspects of agricultural performance (i.e. financial management and administration; human resource management; general planning; customer service).

The survey has confirmed a combination of human-oriented and technology-oriented approaches, as both human and technology aspects are necessary for KM organization.

Farmers have defined role of leadership and process of monitoring as important integrated parts of KM, their necessity for KMM was proved by majority of respondents.

At the end of questionnaire, an estimation of KM model was offered to farmers. According to $30 \%$ of respondents, developed KMM is ready for implementation; however major part ( $70 \%$ of respondents) prefers to reconsider some elements and their combination. It may be explained by the fact that Italian agricultural enterprises have a great differences in the number of staff, level of revenue and needs of information.

\section{Conclusions}

This paper has discussed $\mathrm{KM}$ as a tool for sustaining well-being in rural areas through enhancing performance of small and medium-sized farms and agricultural enterprises, as they have a significant share in the structure of Italian agriculture, compose an economic base of rural areas, and employ a major part of rural population. Therefore, sustainable development or "ability to continue the performance" is considered as a main long-term goal for farmers and a base for well-being in the rural areas.

This study has considered KM as a practical instrument for sustainable performance, and has developed sustainable organisational model of KM for agricultural enterprises. KMM could be a concrete measure for gradual improving quality of life in the rural areas in a long-term perspective.

Used methodology has allowed to answer stated research questions.

The developed model of KM answers the RQ1 and explains the way of application of KM within the rural enterprises, as well as factors and approaches, necessary for its organisation. Thus, according to executed analysis may be said the next.

Any forms of KM organisation are important for sustainable development, and farmers are incentives to apply any practices of KM for improving performance and competitiveness of their enterprises. 
From the theoretical point of view, the follow factors are the most important for functionality rural KM: local knowledge, learning process, knowledge transfer, knowledge sharing; and the main obstacles of KM application in agricultural context are limited time and lack of qualified staff.

Furthermore, theoretically, the most important criteria for sustainable KM model in agriculture are: an ability to provide necessary information in the required time; organisational costs; and level of user's satisfaction. From the practical viewpoint, a positive impact on the agricultural performance is the most expected result and the main criterion of KM sustainability. Practically, a positive impact of KM depends on its organisation. In the same time, the impact of KM cannot be clear, due to intangible character of KM assets and many other factors affecting agricultural performance.

The offered two-fold monitoring is an embedded part to ensure sustainable functioning of the KMM. In turn, sustainable KMM will provide a sustainable contribution to the rural area and to the rural society. Hence, the answer RQ2 is follow: sustainable KM directly contributes to farms and rural enterprises and has indirect impact on the rural well-being. Direct contribution of KM expresses through enhanced and diversified performance, whilst indirect impact means different benefits for society as increased quality of life, improved environmental conditions, strengthened social inclusion and preserved cultural heritage of rural areas. This indirect contribution seems more important for well-being of rural society, because all these benefits could meet the global challenges such as rural-urban migration and poverty reducing.

From a philosophical point of view, using knowledge as a tool for sustainable well-being, on the one hand, coincides with a practical rationality and role of knowledge in it. On the other hand, global usage of information and its role in the society's well-being are the necessary characteristics of the contemporary knowledge-based economy.

\section{References}

Argote L., Ingram P. (2000). Knowledge Transfer: A Basis for Competitive Advantage in Firms. Organizational Behavior and Human Decision Processes, 82(1): 150-169.

Aurum A., Daneshgar F., Ward J. (2008). Investigating Knowledge Management practices in software development organisations - An Australian experience. Information and Software Technology, 50(6): 511-533.

Barney J. (1991). Firm resources and sustained competitive advantage. Journal of management, 17(1): 99-120. 
Berionni B.E. (2013). Regionalizzare la tutela dell'ambiente? Verso una sostenibilità su scala regionale: il caso dell'UE e dell'ASEAN. Rivista di studi sulla sostenibilità, 2: 107-128.

Bhatt G.D. (2001). Knowledge management in organizations: examining the interaction between technologies, techniques, and people. Journal of Knowledge Management, 5(1): 68-75.

Brundtland G.H. (1987). Report of the World Commission on environment and development: “our common future”. United Nations.

Canavari M., Caggiati P., Easter K.W. (eds.) (2012). Economic studies on food, agriculture, and the environment. Springer Science \& Business Media.

Cancila E., Zecca F. (2010). La politica ha bisogno di nuovi strumenti. L'economia scopre la felicità, 5: 44-53.

Carrascal M.J., Pau L.F., Reiner L. (1995). Knowledge and information transfer in agriculture using hypermedia: a system review. Computers and electronics in agriculture, 12(2): 83-119.

Chelli F.M., Ciommi M., Gigliarano C. (2013). The Index of Sustainable Economic Welfare: A Comparison of Two Italian Regions. $1^{\text {st }}$ World Congress of Administrative \& Political Sciences (ADPOL-2012).

Chen L., Fong P.S. (2015). Evaluation of knowledge management performance: An organic approach. Information \& Management, 52(4): 431-453.

Chuang S.H. (2004). A resource-based perspective on knowledge management capability and competitive advantage: an empirical investigation. Expert Systems with Applications, 27(3): 459-465.

Chumg H.F., Cooke L., Fry J., Hung I.H. (2015). Factors affecting knowledge sharing in the virtual organisation: Employees' sense of well-being as a mediating effect. Computers in Human Behavior, 44: 70-80.

Council Regulation (EC) 73/2009 of 15 November 2010, on the application of the Farm Advisory System.

Daly M. (2011). Welfare. Cambridge: Polity.

Diener E., Lucas R.E., Oishi S. (2002). Subjective well-being: The science of happiness and life satisfaction. In: Snyder C.R., Lopez S.J. (eds.). Handbook of positive psychology. Oxford: Oxford University Press (pp. 63-73).

Fleurbaey M. (2015). On sustainability and social welfare. Journal of Environmental Economics and Management, 71: 34-53.

Gupta B., Iyer L.S., Aronson J.E. (2000). Knowledge Management: Practices and Challenges. Industrial Management \& Data Systems, 100(1): 17-21.

Hislop D. (2009). Knowledge management in organisations. A critical introduction. $2^{\text {nd }}$ ed. Oxford: Oxford University Press.

Jennex M.E., Olfman L. (2010). Model of knowledge management success. In: Jennex M.E (2010). Strategies for Knowledge Management Success: Exploring Organizational Efficacy. New York: IGI Global (pp. 14-31).

Johnson M.P. (2017). Knowledge acquisition and development in sustainabilityoriented small and medium-sized enterprises: Exploring the practices, capabilities and cooperation. Journal of Cleaner Production, 142: 3769-3781.

Jordaan A.J., Nell W.T., Zecca F. (2004). Agricultural extension systems for rural development: A case study of the Umbria region, Italy. In: Agricultural Extension Officers Annual Congress, Port Elizabeth, South Africa. 
Kevany K.M., MacMichael M. (2014). Communities of knowledge and knowledge of communities: An appreciative inquiry into rural wellbeing. Gateways: International Journal of Community Research and Engagement, 7(1): 34-51.

Kim T.H., Lee J.N., Chun J.U., Benbasat I. (2014). Understanding the effect of knowledge management strategies on knowledge management performance: A contingency perspective. Information \& Management, 51(4): 398-416.

Krumina I., Krumins G., Rozentale S. (2015). Vidzeme Region of Latvia: Knowledge Management in Micro Enterprises. Procedia-Social and Behavioral Sciences, 213: 781-786.

Kulkarni U.R., Ravindran S., Freeze R.A. (2006). Knowledge Management Success Model: Theoretical Development and Empirical Validation. Journal of Management Information Systems, 23(3): 309-347.

Kumaresan A., Liberona D. (2013). Promoting, Knowledge Sharing and Knowledge Management in Organisations Using Innovative Tools. In: $7^{\text {th }}$ International Conference on Knowledge Management in Organizations: Service and Cloud Computing. Berlin Heidelberg: Springer.

Lakshman C. (2008). Knowledge leadership: Tools for executive leaders. Thousand Oaks: Sage Publications.

Lendzion J.P. (2015). Human Resources Management in the System of Organisational Knowledge Management. Procedia Manufacturing, 3: 674-680.

Maier R. (2007). Knowledge Management Systems: Information and Communication Technologies for Knowledge Management. Berlin: Springer.

Materia V.C. (2012). The Agricultural Knowledge and Innovation System in Italy: dynamics, incentives, monitoring and evaluation experiences. Studies in Agricultural Economics, 114: 71-78.

Mauelshagen C., Smith M., Schiller F., Denyer D., Rocks S., Pollard S. (2014). Effective risk governance for environmental policy making: A knowledge management perspective. Environmental Science \& Policy, 41: 23-32.

Mbo'o-Tchouawou M., Colverson K. (2014). Increasing access to agricultural extension and advisory services: How effective are new approaches in reaching women farmers in rural areas? Nairobi, Kenya: International Livestock Research Institute (ILRI).

Mertins K., Heising P., Vorbeck J. (eds.) (2003). Knowledge management. Concepts and best practices. Berlin: Springer Sciences \& Business Media.

Midgley J. (1995). Social development: The developmental perspective in social welfare. Thousand Oaks: Sage Publications.

Milbourne P. (ed.) (2010) Welfare reform in rural places: Comparative perspectives. Bingley: Emerald Group Publishing Limited.

Nijhof W.J., Heikkinen A., Nieuwenhuis L.F. (2002). Shaping flexibility in vocational education and training. Dortrecht.

Oyemomi O., Liu S., Neaga I., Alkhuraiji A. (2016). How knowledge sharing and business process contribute to organizational performance: Using the fsQCA approach. Journal of Business Research, 69(11): 5222-5227.

Porterfield S.L. (1998). On the precipice of reform: Welfare spell durations for rural, female-headed families. American Journal of Agricultural Economics, 80(5): 994-999. 
Prager K., Labarthe P., Caggiano M., Lorenzo-Arribas A. (2016). How does commercialisation impact on the provision of farm advisory services? Evidence from Belgium, Italy, Ireland and the UK. Land Use Policy, 52: 329-344.

Rasmus D. (2000). Knowledge Management's Role in a Merger. Knowledge Management Review, 3: 30-33.

Rivera W.M., Qamar M.K. (2003). Agricultural extension, rural development and the food security challenge. Rome: Food and Agriculture Organization of the United Nations.

Ryan R.M., Deci E.L. (2001). On happiness and human potentials: A review of research on hedonic and eudaimonic well-being. Annual Review of Psychology, 52: 141-166.

Semali L.M. (2002). What is indigenous knowledge?: Voices from the academy. London: Routledge.

Stiglitz J.E., Sen A., Fitoussi J.P. (2010). Report by the commission on the measurement of economic performance and social progress. Paris: Commission on the Measurement of Economic Performance and Social Progress.

Szirmai A., Naudé W., Goedhuys M. (2011). Entrepreneurship, innovation, and economic development. Oxford: Oxford University Press.

Tseng C.Y., Pai D.C., Hung C.H. (2011). Knowledge absorptive capacity and innovation performance in KIBS. Journal of Knowledge Management, 15(6): 971-983.

Turner R.K., Pearce D., Bateman I. (1994). Environmental economics: an elementary introduction. Harvester Wheatsheaf.

Vagnozzi A. (2009). Italian agricultural extension system: old issues and new ideas. In: XIX European Seminar on Extension Education "Theory and practice of advisory work in a time of turbulences". Assisi, Italy 15-19 September.

Weber B.A., Duncan G.J., Whitener L.A. (eds.) (2002). Rural dimensions of welfare reform. WE Upjohn Institute.

Yang L.R., Huang. C.F., Hsu. T.J. (2014). Knowledge leadership to improve project and organizational performance. International Journal of Project Management, 32(1): 40-53.

Zecca F., Rastorgueva N. (2014). Supply Chain Management and Sustainability in Agri-Food System: Italian Evidence. Journal of Nutritional Ecology and Food Research, 2(1): 20-28.

Zecca F., Rastorgueva N. (2016). Trends and Perspectives of the Information Asymmetry Between Consumers and Italian Traditional Food Producers. Recent Patents on Food, Nutrition \& Agriculture, 8(1): 19-24.

Ziemiańczyk U., Krakowiak-Bal A., Mikuła B. (2014). Knowledge management in the process of building competitiveness and innovativeness of rural areas. Online Journal of Applied Knowledge Management, 2(2): 43-56. 